\title{
Parathyroid Hormone and Lipopolysaccharide Induce Murine Osteoblast-like Cells to Secrete a Cytokine Indistinguishable from Granulocyte-Macrophage Colony-stimulating Factor
}

\author{
Mark C. Horowitz, ${ }^{\star \ddagger}$ David L. Coleman, ${ }^{3}$ Patrick M. Flood, ${ }^{\| \ddagger}$ Thomas S. Kupper, ${ }^{\ddagger}$ and Robert L. Jilka' \\ Departments of * Orthopaedics, ${ }^{\ddagger}$ Dermatology, ${ }^{\S}$ Medicine, and "Pathology (Immunology), Yale University School of Medicine and the \\ Howard Hughes Medical Institute at Yale, New Haven, Connecticut 06510; and 'The Veterans Administration Medical Center, Kansas \\ City, Missouri 64128; and The Department of Biochemistry Kansas University School of Medicine, Kansas City, Kansas 66103
}

\begin{abstract}
Osteoblasts are the cells responsible for the secretion of collagen and ultimately the formation of new bone. These cells have also been shown to regulate osteoclast activity by the secretion of cytokines, which remain to be defined. In an attempt to identify these unknown cytokines, we have induced primary murine osteoblasts with two bone active agents, parathyroid hormone (PTH) and lipopolysaccharide (LPS) and analyzed the conditioned media (CM) for the presence of specific cytokines. Analysis of the CM was accomplished by functional, biochemical, and serological techniques. The data indicate that both PTH and LPS are capable of inducing the osteoblasts to secrete a cytokine, which by all of the techniques used, is indistinguishable from granulocyte-macrophage colony-stimulating factor (GM-CSF). Secretion of GM-CSF is not constitutive and requires active induction. Production of the cytokine is dependent on the dose of PTH or LPS added. It has been demonstrated that the addition of GM-CSF to bone marrow cultures results in the formation of increased numbers of osteoclasts. Therefore, these data suggest that osteoblasts not only participate in bone remodeling by formation of new matrix but may regulate osteoclast activity indirectly by their ability to regulate hematopoiesis.
\end{abstract}

\section{Introduction}

Bone resorption is mediated by the action of mature activated osteoclasts. A number of biological agents are known to stimulate bone resorption in vitro. These agents include peptide hormones (parathyroid hormone), steroids (1,25-dihydroxyvitamin D) certain bacterial products (lipopolysaccharide), and cytokines of immune cell origin. The immune cell products can be derived from at least two cell types: $T$ cells (tumor necrosis factor beta) and macrophages (tumor necrosis factor alpha and interleukin 1) $(1,2)$.

Recent evidence indicates that certain of these agents (parathyroid hormone, PTH; IL-1; and tumor necrosis factor,

Address reprint requests to Dr. Horowitz, Department of Orthopaedics, Yale University School of Medicine, 310 Cedar Street, New Haven, CT 06510.

Received for publication 5 February 1988 and in revised form 13 July 1988.

J. Clin. Invest.

(c) The American Society for Clinical Investigation, Inc. $0021-9738 / 89 / 01 / 0149 / 09 \$ 2.00$

Volume 83, January 1989, 149-157
$\mathrm{TNF}^{1}$ ) require the presence of osteoblasts to activate osteoclasts to resorb bone $(3,4)$. The physical presence of the osteoblast can be replaced by osteoblast-conditioned media, indicating that the osteoblast can interact with the osteoclast or osteoclast precursors, via release of a cytokine (s) (5-7). The nature of the molecules secreted by the osteoblast that are responsible for osteoclast activation and subsequent bone resorption are poorly enumerated. These cytokines may have different target cells resulting in multiple pathways leading to osteoclast activation. Certain of these biological agents may activate existing osteoclasts directly, while others may induce the formation of new osteoclasts from resident progenitors. It has been demonstrated that granulocyte-macrophage colonystimulating factor (GM-CSF), a product of T cells, endothelial cells, and keratinocytes (8-10), and macrophage colony-stimulating factor (M-CSF), a product of L cells (11), do not directly induce bone resorption (12), but rather induce the increased formation of osteoclasts from cultured bone marrow cells, suggesting that these cytokines can augment resorption by increasing the number of osteoclasts available for activation (13).

Previously; we have found that conditioned media derived from both 17-d-old fetal rat long bones or isolated neonatal murine calvarial cells, stimulated with lipopolysaccharide (LPS) contains T cell growth factor activity (TCGF) as measured by proliferation of a TCGF responsive $T$ cell line. This activity is however, restricted in its pattern of $\mathrm{T}$ cell activation (14). This observation is unusual in two regards. Although activated $\mathrm{T}$ cells are known to be the primary source of TCGF activity (IL-2, IL-4) (15-17), mature T cells are absent in 17-d-old fetal rat long bones (18). Second, LPS is not known to directly activate $T$ cells to proliferate or secrete TCGF (19). These data suggests that it is the bone cells and not resident immune cells in the bones that are responsible for the production of this unusual TCGF activity. This is supported by data showing that $\mathrm{CM}$ from in vitro cultures of bone marrow depleted femurs from endotoxin injected adult mice produce GM-CSF activity (20). It is therefore important to identify the cellular source of this cytokine, determine the signals that regulate its release, and compare this activity to other well characterized TCGFs.

We show that isolated murine calvarial cells that display an osteoblastic phenotype can be induced with either PTH or LPS

1. Abbreviations used in this paper: CM, conditioned media; GFHPLC, gel filtration HPLC; GM-CSF, granulocyte macrophage CSF; KTGF, keratinocyte-derived T cell growth factor; M-CSF, CSF-1, macrophage CSF; RP-HPLC, reverse phase HPLC; TCGF, T cell growth factor; TGF $\beta$, transforming growth factor beta; TNF, tumor necrosis factor. 
to produce a cytokine that has functional, chemical, and serological properties indistinguishable from GM-CSF. GM-CSF may represent one of the coupling factors that link bone resorption with bone formation. The role of osteoblast-derived cytokines as paracrine modulators of osteoclast activity and hematopoiesis is discussed. These data support the idea that a strong association exists between the cells of the immune system and the cells of the skeletal system and that the interactions between cells of these two systems are mediated, at least in part, by cytokines.

\section{Methods}

Cells. Monolayer cultures of murine calvarial cells were prepared as previously described (21). Our technique is a modification of the basic method described by Wong and Cohn (22). Briefly, calvaria from 3 to 5-d-old C57BL/6J mice were pretreated with EDTA in PBS for $30 \mathrm{~min}$. The calvaria were then subjected to sequential enzymatic digestion using CLS II bacterial collagenase (Cooper Biomedical, Malvern, PA) at $180 \mathrm{U} / \mathrm{ml}$ in PBS over a 50 -min period. Cells released after the first 10-min digestion were designated fractions 1 and 2; cells released after the second 10-min digestion period were designated fractions 3 and 4 and cells released in the third 10-min digestion period were designated fractions 5 and 6 . Following growth to confluence, calvarial cells released early in the initial collagenase digestion (fraction $1+2$ ) retain a fibroblastic morphology and release little $T$ cell stimulating activity (data not shown). Fractions 3-6 are routinely used as the starting population of cells. Cells were washed twice in initial culture media (BGJ with 5\% FCS), counted and plated at high $\left(2 \times 10^{5} / \mathrm{cm}^{2}\right)$ or low $\left(0.4 \times 10^{5} / \mathrm{cm}^{2}\right)$ density. When examined immediately after isolation the released cells in fractions 3-6 are enriched for cells expressing the osteoblastic phenotype $(23,24)$. When seeded at high density the capacity of the calvarial cells to form osteoclasts in response to PTH is retained (21). Low but detectable numbers of macrophage-like cells are present (25), in addition to the osteoblasts that predominate. The low density population is characterized by its inability to develop osteoclasts in response to resorptive agents and macrophages are undetectable as measured by staining. After growth to confluence the low density population is highly enriched for osteoblasts as evidenced by in vitro bone formation and a rise in cAMP in response to PTH $(26,27)$. Growth to confluence by the low density seeded cells, by definition, selects for highly proliferative cells consistent with osteoblastic progenitors.

The T cell lines HT-2 and CTLL-2 were originally obtained from Dr. P. Marrack (National Jewish Hospital, Denver, CO) through Dr. Charles A. Janeway, Jr. (Yale University School of Medicine). CT-6 cells were obtained from Dr. David McKean, Mayo Clinic, Rochester, MN. All three of these lines are Thy-1 positive and express high affinity receptors for IL-2 $(28,29)$. HT-2 cells are a clone derived from a helper cell line, while CTLL- 2 and CT- 6 are clones derived from cytotoxic T cells (30). The $T$ cell lines were maintained by weekly feeding with Click's Eagle's Hanks' amino acid medium (Irvine Scientific, Santa Ana, CA) supplemented with $10 \%$ FCS and 5-10\% rat-derived TCGF. Rat TCGF was prepared by incubating rat spleen cells in RPMI 1640 (Gibco Laboratories, Grand Island, NY) medium $\left(5 \times 10^{6}\right.$ cells $\left./ \mathrm{ml}\right)$ with Con A $(2.5 \mu \mathrm{g} / \mathrm{ml})$ for $48 \mathrm{~h}$. The medium was harvested, sterile filtered $(0.45 \mu \mathrm{m})$, and stored at $-20^{\circ} \mathrm{C}$ until use. The rat TCGF was treated with alpha methyl-D-mannoside $(20 \mathrm{mg} / \mathrm{ml})$ before use to eliminate any non-bound Con A. All preparations were pretested for T cell growth before use.

Concanavalin A activated spleen $T$ cells blasts. Spleen $\mathrm{T}$ cells were prepared as previously described (31). Briefly, spleen cells $\left(50 \times 10^{6}\right)$ were incubated for $60 \mathrm{~min}$ at $4^{\circ} \mathrm{C}$ on plastic petri dishes (Fisher Scientific, Springfield, NJ) which are coated with affinity purified goat-antimouse Ig. After the incubation, the nonadherent cells were collected and used as the $\mathrm{T}$ cell-enriched population. This population is $>95 \%$
Thy $-1^{+}$by immunofluorescence (32). The cells were cultured at 5 $\times 10^{6} / \mathrm{ml}$ for $48 \mathrm{~h}$ in the presence of $2.5 \mu \mathrm{g} / \mathrm{ml}$ of Con A (Sigma Chemical Co., St. Louis, MO). The cells were collected, washed, and blasts were enriched by passage through a single step lymphocyte separation medium (LSM) gradient (Organon Teknika Corp., Durham, NC). The cells recovered at the media-LSM interface were used immediately as targets for the proliferation assay.

Preparation of bone cell conditioned media (CM). Bone cell monolayers were washed with serum free BGJ media containing $10 \mathrm{mg} / \mathrm{ml}$ BSA, $1 \mu \mathrm{g} / \mathrm{ml}$ insulin and $1 \mu \mathrm{g} / \mathrm{ml}$ transferrin. Then, either PTH (1-84 b-PTH $\sim 5,000 \mathrm{U} / \mathrm{ml}$ purified to homogeneity from bovine glands by the Calcium Research Laboratory, V.A. Medical Center, Kansas City; MO) or LPS (055:B5; Difco Laboratories, Detroit, MI) at the indicated concentrations was added. The PTH was tested for the presence of endotoxin by the Limulus amebocyte lysate assay and was found to have no detectable level of endotoxin. This assay can detect endotoxin to $<100 \mathrm{pg} / \mathrm{ml}$ and can detect as low as $10 \mathrm{pg} / \mathrm{ml}$. The cells were incubated for either 48 or $96 \mathrm{~h}$ at which time the culture supernatants were recovered, sterile filtered $(0.45 \mu \mathrm{m})$, and stored at $-20^{\circ} \mathrm{C}$.

Antibodies. 11B11, a monoclonal antibody to BSF-1/IL-4 (33), was provided as a sterile culture supernatant by Dr. W. Paul of the National Institutes of Health (NIH). Monoclonal antibodies to the murine IL-2 receptor, in the form of sterile culture supernatant (PC-61 and alpha 7D4) were provided by Dr. C. A. Janeway, Jr. of Yale University. S4B6, a monoclonal antibody to murine IL-2 (17) was provided as a high-titer ascites preparation by Dr. Tim Mosmann (DNAX Research Institute, Palo Alto, CA). A polyclonal goat antibody to murine GMCSF was provided by Dr. Jolanda Schreurs (DNAX Research Institute). This antibody was raised against purified recombinant murine GM-CSF. This antibody shows no cross-reactivity with IL-2, IL-3, IL-4, M-CSF or any other known cytokine. ${ }^{2,3}$

Cytokines. Murine recombinant GM-CSF was obtained from Dr. Frank Lee (DNAX). Affinity purified BSF-1/IL-4 was provided by Dr. W. Paul (NIH). Recombinant human IL-2 was purchased from Amgen Biologicals (Thousand Oaks, CA).

$T$ cell growth factor assay. HT- 2 cells are a cloned $T$ cell line that proliferates in response to IL-2, IL-4, and GM-CSF $(29,30)$. CTLL-2 cells are a cloned $T$ cell line that proliferates in response to IL-2 and high concentrations of IL-4 (33a). CT-6 cells are a cloned T cell line that responds to IL-2 (34) and high concentrations of TNF $\alpha .^{4} \mathrm{~T}$ cell lines were recovered from continuously growing maintenance cultures and washed three times in PBS with 2\% FCS. Washed, viable T cells at a concentration of $2 \times 10^{4}$ cells/well were plated in 96 well flat bottom tissue culture plates (Costar, Cambridge, MA) to which test CM at the appropriate concentration was added and a final volume of $200 \mu \mathrm{l}$ was achieved with complete media. Triplicate cultures were incubated for $48 \mathrm{~h}$ at $37^{\circ} \mathrm{C}$ in $5 \% \mathrm{CO}_{2}$. Proliferation was determined by the incorporation of $\left[{ }^{3} \mathrm{H}\right]$ thymidine $(1 \mu \mathrm{Ci} /$ well, $70-85 \mathrm{Ci} / \mathrm{mmol})$, which was added during the last $4 \mathrm{~h}$ of culture. The cultures were harvested on an automated sample harvester (Cambridge Technologies, Cambridge, MA). Radioactivity was measured with a scintillation spectrometer (Beckman Instruments, Inc., Fullerton, CA). Data is presented as the mean of triplicate cultures \pm SEM. All data presented are representative of multiple experiments.

Gel filtration high pressure liquid chromatography. Samples were analyżed by injection into a Bio-Sil TSK 125 (Bio-Rad Laboratories, Richmond, CA) column using a Bio-Rad gradient processor HPLC system. The material was eluted with PBS $(0.15 \mathrm{M} \mathrm{NaCl}, 10 \mathrm{mM}$ $\mathrm{NaH}_{2} \mathrm{PO}_{4}, \mathrm{pH} 7.4$ ) at a flow rate of $1.0 \mathrm{ml} / \mathrm{min}$ and $0.4-\mathrm{ml}$ fractions were collected in $12 \times 75 \mathrm{~mm}$ polypropylene tubes. The fractions obtained following GF-HPLC were tested for functional activity. The

2. Schreurs, J., unpublished observation.

3. Horowitz, M., unpublished observation.

4. Pallidino, M. Presented at the 2nd International Workshop on Cells and Cytokines in Bone and Cartilage, Davos, Switzerland, 1988. 
column was calibrated using chromatography molecular weight standards (Bio-Rad Laboratories).

Reverse-phase HPLC. Reverse-phase HPLC was performed with a $250 \times 4.6 \mathrm{~mm}$ HiPore RP318 column (Bio-Rad Laboratories). Solvent A was $0.05 \%$ trifluoroacetic acid in water and solvent B was $0.05 \%$ trifluoroacetic acid in acetonitrile. The column was equilibrated in solvents A and B at a ratio of 25:75. All reagents were HPLC grade. Samples were filtered with a $0.45-\mu \mathrm{m}$ fluoropolymer HPLC filter (Gelman Sciences, Ann Arbor, MI), and injected into the $\mathrm{C} 18$ column. A linear gradient from 25 to $70 \%$ solvent $B$ over 45 min was initiated at a flow rate of $1.0 \mathrm{ml} / \mathrm{min}$ and $1.0-\mathrm{ml}$ fractions were collected in 12 $\times 75-\mathrm{mm}$ polypropylene tubes. Optical density was continuously monitored at $220 \mathrm{~nm}$. Samples were dried in a vacuum centrifuge (Savant, Farmingdale, NY) and resuspended in media before assay.

Horizontal isoelectric focusing. Cell-free supernantants were extensively dialyzed against deionized water. Ampholytes, pH 3-10 (BioRad Laboratories) were added to $1 \mathrm{ml}$ of the retentate at a final concentration of $2 \%$ (vol/vol). This material was added to a $20 \times 20-\mathrm{cm}$ electrofocusing tray that contained $50 \mathrm{ml}$ electrofocusing gel (Bio-Rad Laboratories) with $2 \%$ ampholytes pH 3-10. The anode was $20 \mathrm{mM}$ aspartic acid and $20 \mathrm{mM}$ glutamic acid. The cathode solution was $2 \mathrm{M}$ ethanolamine, $20 \mathrm{mM}$ lysine free base, and $20 \mathrm{mM}$ arginine. Electrofocusing was conducted in a Bio-Phoresis horizontal electrophoresis cell (Bio-Rad Laboratories) at $4-10^{\circ} \mathrm{C}$ for $4 \mathrm{~h}$ at a constant power of 14 $\mathrm{W}$. At the completion of the run, the fractions were removed, $1.5 \mathrm{ml}$ of $\mathrm{H}_{2} \mathrm{O}$ was added, and the $\mathrm{pH}$ was measured with a combination $\mathrm{pH}$ electrode. Each fraction was subsequently dialyzed extensively against $10 \mathrm{mM} \mathrm{Na} \mathrm{HPO}_{4} / \mathrm{NaH}_{2} \mathrm{PO}_{4}, \mathrm{pH} 7.4$, filtered through a $0.45-\mu \mathrm{m}$ fluoropolymer membrane (Gelman Sciences), and assayed for TCGF activity.

\section{Results}

Bone cells were seeded at either high or low density and allowed to grow to confluence. A comparison between low and high density cells was made because the populations of cells which arise from these initial seeding densities are distinct (see Methods). The bone cell monolayers were washed and recultured for either 48 or $96 \mathrm{~h}$ in the presence of either lipopolysaccharide (LPS, $10 \mu \mathrm{g} / \mathrm{ml}$ ) or parathyroid hormone (PTH, 10 $\mathrm{nM})$. The CM was collected and tested for its ability to induce
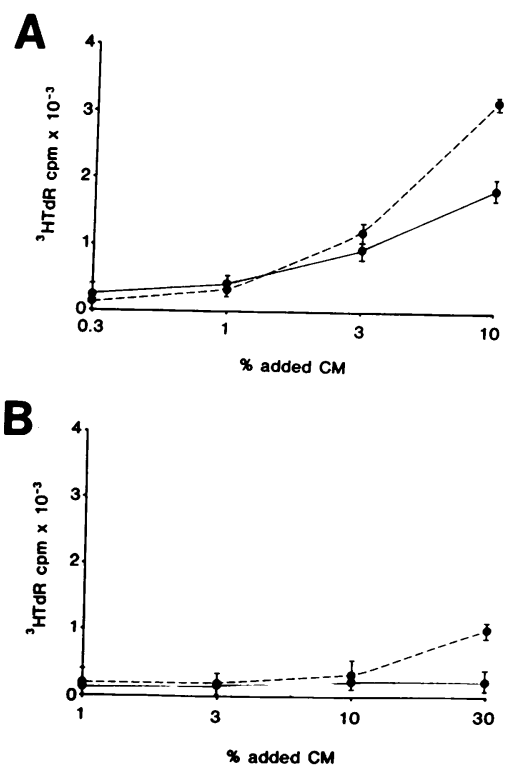

Figure 1. Dose-response analysis of CM from high density seeded bone cell cultures induced with either LPS or PTH. CM derived from cultures of high density seeded bone cells induced with $(A)$ $10 \mu \mathrm{g} / \mathrm{ml} \mathrm{LPS}$ or $(B) 10$ nM PTH for either 48 $(-\bullet-)$ or $96(-\bullet-) \mathrm{h}$ were assayed for their ability to induce $T$ cell proliferation. Increasing concentrations of CM were cocultured with the TCGF dependent $T$ cell clone HT-2 (2 $\times 10^{4}$ cells/well) for 48 $h$ in a final volume of $200 \mu$ il. Controls: HT-2 cells plus media $113 \pm 15$ SEM.
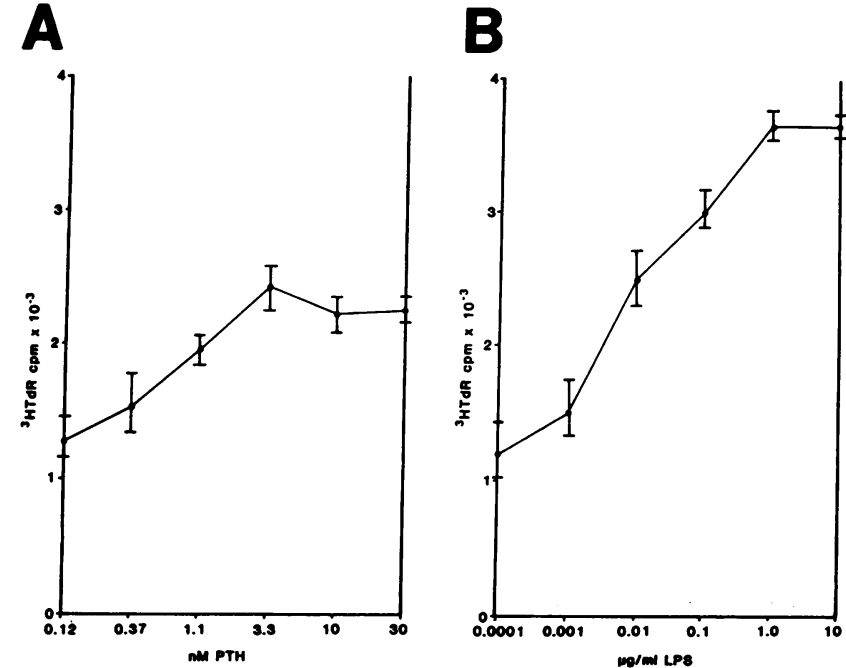

Figure 2. Dose-response analysis of CM from high density seeded bone cell cultures induced with varying concentrations of PTH and LPS. CM derived from cultures of high density seeded bone cells induced with $(A)$ PTH or $(B)$ LPS for $96 \mathrm{~h}$ were assayed for their ability to induce $\mathrm{T}$ cell proliferation. CM $(50 \mu \mathrm{l}, 25 \% \mathrm{vol} / \mathrm{vol})$ was cocultured with the TCGF-dependent T cell clone HT- $2\left(2 \times 10^{4}\right.$ cells/ well) for $48 \mathrm{~h}$ in a final volume of $200 \mu \mathrm{l}$. Controls: HT-2 cells plus media $540 \pm 94$ SEM.

HT-2 cell proliferation as measured by the uptake of $\left[{ }^{3} \mathrm{H}\right]-$ thymidine. Data in Fig. $1 A$ show that CM from high density cells induced for either 48 or $96 \mathrm{~h}$ of culture with LPS stimulate HT-2 cells in a dose-dependent manner. However, PTH fails to induce any detectable HT-2 stimulating activity below $30 \%$ added CM at either time point tested (Fig. 1 B). Only at 96 $\mathrm{h}$ and $30 \%$ added $\mathrm{CM}$ can any HT-2 stimulating activity be detected. CM from the high density cells grown in the absence of inducing agents fails to stimulate HT-2 cell proliferation (data not shown). This suggests that the osteoblast-like cells are not constitutively producing the HT-2 stimulating activity and secretion can only be achieved by active induction of the cells. LPS or PTH added directly to the HT-2 cells fails to induce proliferation (data not shown), indicating that the carryover of inducer from the bone cell cultures to the assay cultures is not responsible for the $T$ cell activation.

To directly compare the ability of PTH with LPS to induce HT-2 stimulating activity, varying doses of the reagents were added to confluent monolayers of high density cells and cultured for $96 \mathrm{~h}$. The CM was collected and tested for its ability to induce HT-2 cell proliferation. The data in Fig. 2 show that PTH induces the secretion of HT-2 stimulating activity in a dose-dependent fashion from 0.12 to $3.3 \mathrm{nM}$. LPS was also capable of inducing HT-2 stimulating activity in dose-dependent fashion from 0.0001 to $1 \mu \mathrm{g} / \mathrm{ml}$. These data suggests that at low concentrations PTH and LPS are approximately equal in their ability to induce HT-2 stimulating activity from the bone cells. However, LPS is stimulatory over a broader concentration range.

We next investigated whether a similar pattern of responsiveness was observed using calvarial cells initially seeded at low density and grown to confluence. These cells are regarded as highly enriched for osteoblasts and contain undetectable numbers of osteoclasts and macrophages. Conditioned media 

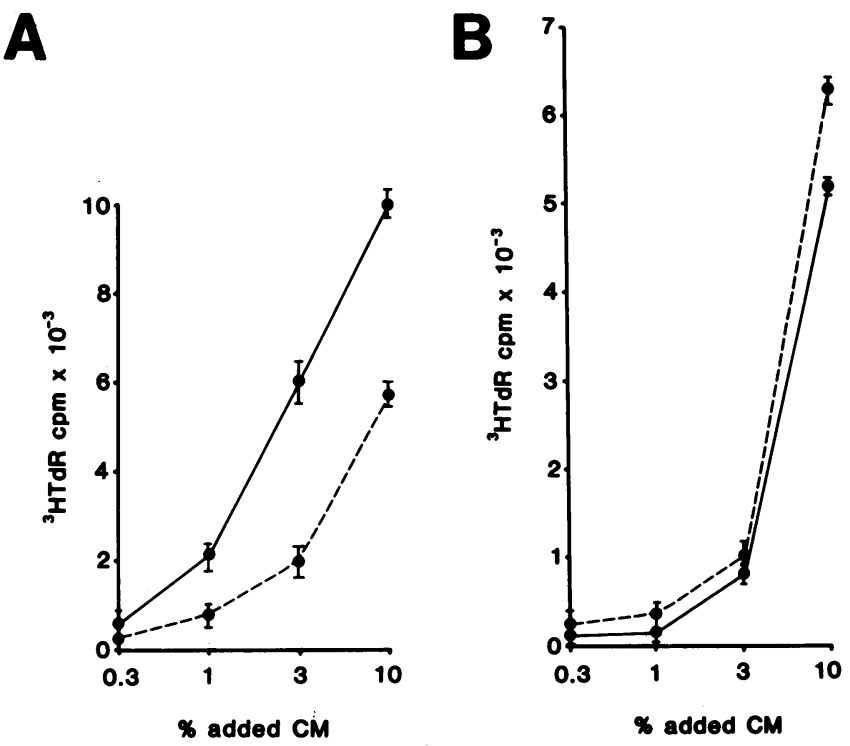

Figure 3. Dose-response analysis of CM from low density seeded bone cell cultures induced with either LPS or PTH. CM derived from cultures of low density seeded bone cells, which are highly enriched for growing preosteoblastic cells, were induce with $(A) 10$ $\mu \mathrm{g} / \mathrm{ml} \mathrm{LPS} \mathrm{or}(B) 10 \mathrm{nM}$ PTH for either $48(-\bullet-)$ or $96(-\bullet-) \mathrm{h}$ were assayed for their ability to induce $\mathrm{T}$ cell proliferation. Increasing concentrations of $\mathrm{CM}$ were cocultured with the TCGF dependent T cell clone HT- $2\left(2 \times 10^{4}\right.$ cells/well $)$ for $48 \mathrm{~h}$ in a final volume of $200 \mu$ ls. Controls: HT-2 cells plus media $113 \pm 15$ SEM.

from low density cells released HT-2 stimulating activity in response to PTH or LPS. This activity is seen as a dose-dependent increase in the proliferative response of HT-2 cells (Fig. 3 $A)$. These data are similar to those seen with the high density cells (Fig. $1 A$ ) however, 3 - to 10 -fold more activity is being secreted by the low density population (depending on the particular experiment). In contrast to the high density cells, which are poor responders to PTH (Fig. $1 \mathrm{~B}$ ), low density cells when cultured with $10 \mathrm{nM}$ PTH produce $\mathrm{CM}$, which is highly stimulatory for HT-2 cells (Fig. $3 \mathrm{~B}$ ). No significant difference in the amount of activity is noted with increasing time. This suggests that activation with either LPS or PTH occurs early in the culture period and peaks rapidly. Low density calvarial cells cultured in the absence of either LPS or PTH, similar to the high density cells, fail to produce any HT-2 stimulating activity. These data indicate little or no constitutive level of HT-2 stimulating activity by the osteoblast-like cells. It further suggests that an active event of induction must occur before the cytokine(s) is secreted. In all experiments to date LPS has induced more HT-2 stimulating activity than PTH although the absolute level of proliferation may vary from experiment to experiment.

The HT-2 cell stimulating activity observed is unusual in two regards. First, $T$ cells, which are the primary source of TCGF, have not been reported to be present in calvarial bone cell preparations. In addition, 1-d-old neonatal mice have few circulating mature $\mathrm{T}$ cells that could contribute to this response (35). Second, LPS has not been reported to activate $T$ cells nor induce secretion of TCGFs (19). This apparent dichotomy prompted us to characterize the HT-2 stimulating activity present in the osteoblast-enriched CM.
Since the subline of HT-2 cells used in these studies responds only to IL-2, IL-4, and granulocyte-macrophage colony stimulating factor (GM-CSF) (29) it was necessary to distinguish among these cytokines. It should be noted that HT-2 cells respond to $T$ cell derived, keratinocyte derived, and recombinant forms of GM-CSF. However, all HT-2 sublines as well as $\mathrm{T}$ cells in general do not necessarily respond to GMCSF (36).

We tested the chemical properties of the HT-2 stimulating activity to determine whether the material released by osteoblasts was chemically identical to other known TCGFs (i.e., IL-2, IL-4, or GM-CSF). To determine the approximate molecular weight, gel filtration HPLC was performed on CM from LPS-activated, low density seeded cells. CM was separated by size on a TSK 125 gel filtration HPLC column and assayed for functional activity by inducing HT-2 cell proliferation. A peak of functional activity is observed between fractions 4 and 8 with maximum activity in fraction 6 (Fig. 4). This peak corresponds to a molecular weight range of between 20 to 30,000 with a peak at 27,000 . These data make it unlikely that the HT-2 stimulating activity is CSF-1, which has a molecular weight of 70,000. In addition, CM rich in CSF-1 fails to stimulate HT-2 cell proliferation. ${ }^{3}$ Because no other peaks of activity can be detected it is also unlikely that a small molecular weight molecule could account for the observed proliferation. However, IL-2, IL-4, and GM-CSF can all be found in this molecular weight range.

The isoelectric point of the HT-2 stimulating activity was measured as described in Methods. CM from LPS-activated low density seeded osteoblasts was used. After horizontal isoelectric focusing, each fraction was assayed for biological activity at 25 and $12.5 \%$ (by volume). The results at the two concentrations were similar. Data in Fig. 5 show the HT-2 stimulating activity to be maximal in fraction 21 , which corresponds

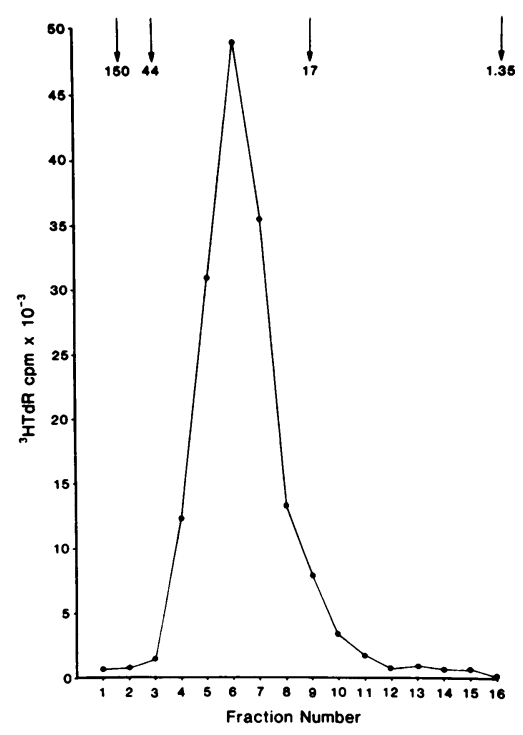

Figure 4. Gel filtration HPLC analysis of CM derived from low density seeded bone cell cultures. CM derived from low density seeded bone cells induced with $10 \mu \mathrm{g} / \mathrm{ml}$ of LPS for 96 $h$ was separated on a TSK 125 gel filtration HPLC column. Individual fractions were assayed for their ability to induce $T$ cell proliferation. Fractions (50 $\mu$, $25 \% \mathrm{vol} / \mathrm{vol}$ ) were cocultured with the TCGF dependent $T$ cell clone HT-2 $\left(2 \times 10^{4}\right.$ cells/ well) for $48 \mathrm{~h}$ in a final volume of $200 \mu$ l. Data are representative of multiple experiments. Controls: HT- 2 cells plus media $886 \pm 5$ SEM, HT-2 cells plus 3 $\mathrm{U} / \mathrm{ml}$ of rIL-2, $126,100 \pm 6,300$ SEM. 


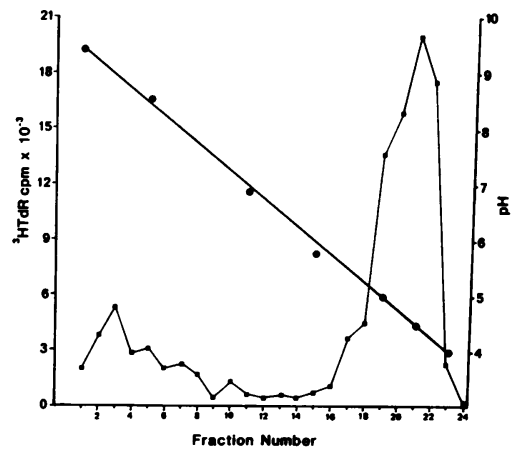

Figure 5. Isoelectric focusing analysis of $\mathrm{CM}$ derived from low density seeded bone cell cultures. CM derived from low density seeded bone cells induced with $10 \mu \mathrm{g} / \mathrm{ml}$ of LPS for 96 $\mathrm{h}$ was dialyzed extensively against low conductivity water and separated by horizontal isoelectric focusing. A $\mathrm{pH}$ range from 4.0 to 8.5 was assayed to detect the presence of isoelectric forms at the extremes of physiologic pH. Individual samples were assayed for their ability to induce $\mathrm{T}$ cell proliferation. Fractions $(25 \mu \mathrm{l}, 12.5 \% \mathrm{vol} / \mathrm{vol})$ were cocultured with the TCGF-dependent $\mathrm{T}$ cell clone HT-2 (2 $\times 10^{4}$ cells/well) for $48 \mathrm{~h}$ in a final volume of $200 \mu \mathrm{l}$. Data are representative of multiple experiments. Controls: HT-2 cells plus media $276 \pm 241$ SEM

to a pI of 4.4, and is detectable from pI 5.0 to 4.2 . A wide $\mathrm{pH}$ range (4.0 to 8.5$)$ was assayed to enhance detection of isoelectric forms at the extremes of physiologic pH. An isoelectric point in this range distinguishes the osteoblast-derived material from IL-4, which has a pI of 6.3 (37). However, a pI in this range is similar to that of IL-2 and GM-CSF.

CM was next analyzed by reverse-phase HPLC using a C-18 column, while protein was monitored by absorbance at $220 \mathrm{~nm}$. Serum free CM from LPS activated low density seeded osteoblast-like cells was used. A single major peak of protein is observed in fractions $19-20$ reaching a maximum in fraction 19 . This peak of activity corresponds to an acetonitrile concentration of between 44 and 45\% (not shown). The functional activity of each fraction was tested for biological activity by induction of HT-2 cell proliferation. Data in Fig. 6 show the peak of functional activity is in fraction 23 , which represents an acetonitrile concentration of $48-49 \%$. No other HT-2 stimulating activity can be detected over the gradient. It has been

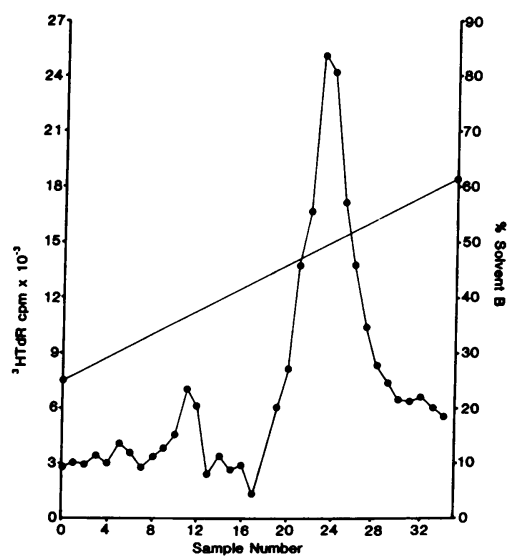

Figure 6. Reverse-phase HPLC analysis of CM derived from low density seeded bone cell cultures. CM derived from low density seeded bone cells induced with $10 \mu \mathrm{g} / \mathrm{ml}$ of LPS for 96 $\mathrm{h}$ was separated on a C-18 reverse-phase column. A gradient of acetonitrile $(25-70 \%)$ and water with TFA was used to elute the column. Individual fractions were recovered from the column, and lyophilized by vacuum centrifugation. The fractions were resuspended in tissue culture media and assayed for their ability to induce $\mathrm{T}$ cell proliferation. Fractions $(100 \mu \mathrm{l}, 50 \% \mathrm{vol} / \mathrm{vol})$ were cocultured with the TCGF-dependent T cell clone HT- $2\left(2 \times 10^{4}\right.$ cells/well $)$ for $48 \mathrm{~h}$ in a final volume of $200 \mu \mathrm{l}$. Data are representative of multiple experiments. Controls: HT-2 cells plus media 4,721 250 SEM.

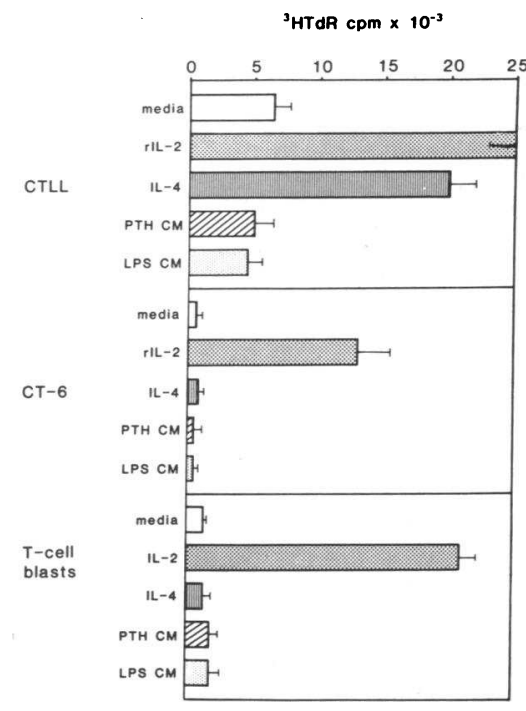

Figure 7. Functional analysis of $\mathrm{CM}$ derived from low density seeded bone cell cultures induced with either LPS or PTH. CM derived from cultures of low density seeded bone cells, were induced with either $10 \mu \mathrm{g} / \mathrm{ml}$ LPS or $10 \mathrm{nM}$ PTH for $96 \mathrm{~h}$ and assayed for their ability to induce proliferation of various indicator T cells. CM (50 $\mu \mathrm{l}, 25 \% \mathrm{vol} / \mathrm{vol}$ ) was cocultured with the TCGF-dependent $\mathrm{T}$ cell clones CTLL and CT-6 $\left(2 \times 10^{4} /\right.$ cells per well $)$ and Con A-activated $T$

cell blasts $\left(10^{5} /\right.$ well) for $48 \mathrm{~h}$ in a final volume of $200 \mu$ l. The bone cell $\mathrm{CM}$ was pretested for its ability to stimulate HT-2 cells and was found to be positive. rIL-2 was used at $2.5 \mathrm{U} / \mathrm{ml}$ while affinity purified IL-4 was used at $100 \mathrm{U} / \mathrm{ml}$.

shown that IL-4 elutes at $42 \%$ acetonitrile suggesting that it is distinct from the osteoblast-derived HT-2 stimulating activity (37). However, both IL-2 and GM-CSF elute at $48-49 \%$ acetonitrile. The data obtained from reverse-phase HPLC supports that obtained from isoelectric focusing in suggesting that the HT-2 stimulating activity is due to GM-CSF or IL-2.

To further distinguish these activities, osteoblast CM was tested for its ability to stimulate the growth of other $T$ cells with well-defined growth factor requirements. CM from 48-h cultures of low density seeded osteoblast-like cells induced with either LPS or PTH was cocultured with several other TCGF-dependent T cell lines including: (a) CTLL-2 cells, (b) CT -6 cells, and (c) Con A activated T cell blasts. The data in Fig. 7 show that, at all concentrations tested, the osteoblast derived CM, which had previously been shown to stimulate the proliferation of HT-2 cells, failed to stimulate any of the other $\mathrm{T}$ cell preparations. All of the cells respond to rIL-2 indicating that the cells are capable of responding to the appropriate growth signal. CTLL cells are known to respond to both IL- 2 and IL- 4 while CT- 6 and Con A activated T cell blasts respond to IL-2 (34). ${ }^{3}$ These data suggest that the HT-2 stimulating activity present in the osteoblast $\mathrm{CM}$ is neither IL-2 nor IL-4.

Antibody blocking studies were then used as a tool to further characterize the HT-2 stimulating activity. To demonstrate specificity of the various antibodies, they were tested independently for their ability to block functional activity of their corresponding cytokines. Antibodies with specificities for the murine IL-2 receptor (PC61 + 7D4), IL-4 (11B11), and GM-CSF (anti-GM-CSF) were added to cultures of HT-2 cells stimulated with rIL-2, affinity purified IL-4 or rGM-CSF, respectively. Data in Fig. 8 show that each individual antibody is able to block that cytokine for which it has specificity and fail to exhibit any nonspecific blocking activity. Similar specificity data has been obtained using S4B6, an antibody to murine IL-2 (data not shown) (29). These data establish the specificity of the antibodies used. A similar experiment was then con- 

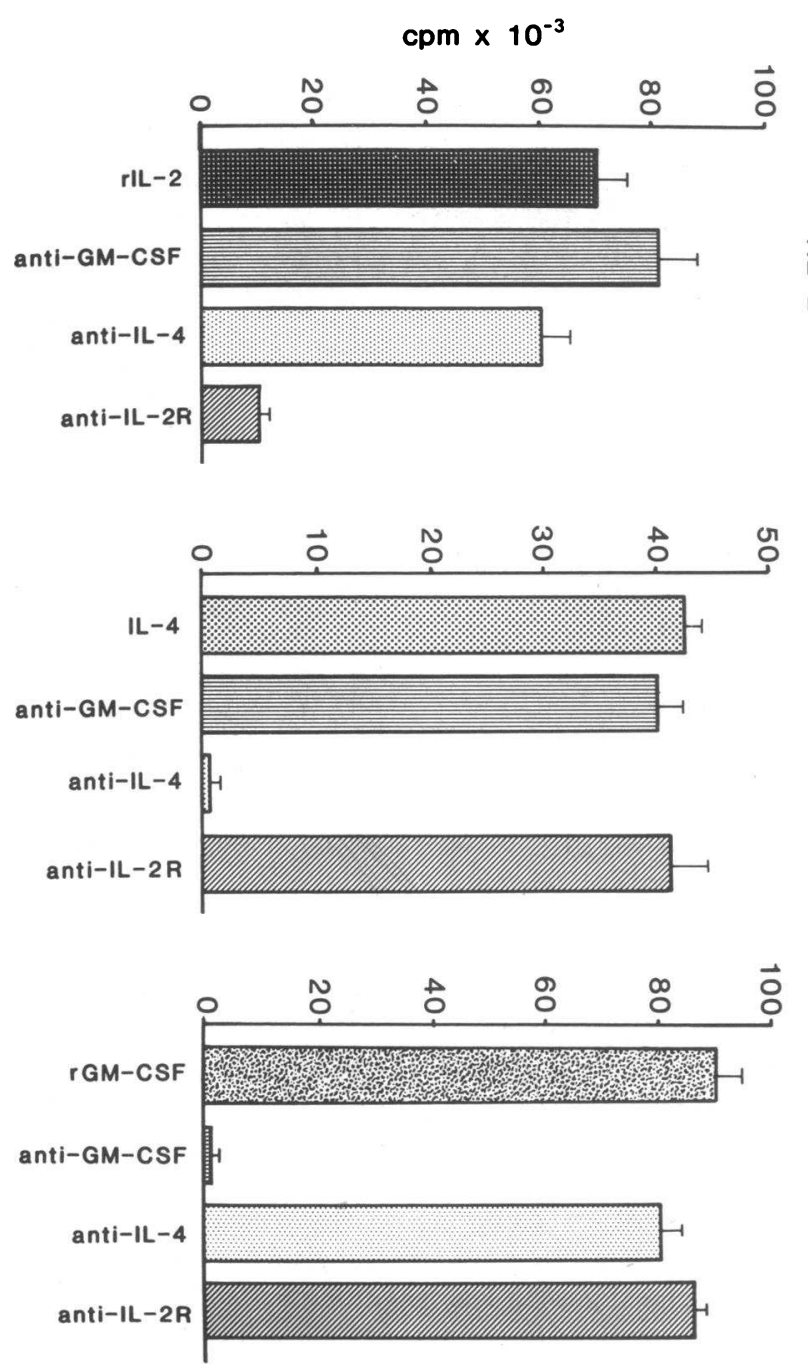

Figure 8. Antibody specificity. Anti-IL-4 (11B11 at 1:1,000 dilution), anti-IL-2R (alpha 7D4 + PC - 61 at 1:10 dilution) and anti-GMCSF (at 1:1000 dilution) were tested for their ability to specifically inhibit their corresponding cytokine. To test for neutralizing activity, HT- 2 cells $\left(2 \times 10^{4}\right.$ cells/well) were cocultured with rIL-2 $(2.5$ $\mathrm{U} / \mathrm{ml})$, affinity purified IL-4 $(100 \mathrm{U} / \mathrm{ml})$, or rGM-CSF $\left(10^{-6}\right.$ dilution; $\sim 1-5 \mathrm{U} / \mathrm{ml}$ ) in the presence or absence of the neutralizing antibodies for $48 \mathrm{~h}$. Controls: HT- 2 cells plus media $980 \pm 60$ SEM.

ducted using the CM from both LPS (Fig. $9 A$ ) and PTH (Fig. 9 $B$ ) induced low density seeded osteoblast cultures. Varying concentrations of $\mathrm{CM}$ derived from the two groups of induced osteoblasts was cocultured with HT-2 cells to which the neutralizing antibodies were added. The ability to inhibit the proliferative response of the HT-2 cells by the antibodies was measured. These data are identical for both the LPS and the PTH-induced osteoblast CM. Conditioned media in the absence of any blocking antibody induces a dose-dependent increase in the proliferative response of the HT-2 cells similar to that already described. The addition of antibodies capable of neutralizing either IL-2 or IL-4 fail to inhibit the proliferative response of the HT-2 cells. However, addition of antibody neutralizing for GM-CSF blocks to background the proliferative response of the HT- 2 cells at all concentrations tested. This observation agrees with the functional and biochemical data in showing that the osteoblast derived HT-2 stimulating activity is indistinguishable from GM-CSF.

\section{Discussion}

This work demonstrates that a population of murine calvarial cells highly enriched in osteoblasts can be activated with either PTH or LPS to secrete an HT-2 cell (T cell) growth factor. The data indicate that the growth factor secreted by the osteoblasts is indistinguishable from granulocyte-macrophage colony stimulating factor. This conclusion is supported by functional, biochemical, and serologic data. The HT-2 stimulating activity secreted by either PTH or LPS activated osteoblasts have very similar functional and biochemical properties. At equimolar concentrations, PTH and LPS induce the cells to secrete approximately equal amounts of GM-CSF. However, increasing concentrations of LPS induces the secretion of more cytokine. This is not the case for PTH, which reaches maximal stimulation at a level of released cytokine well below the maximum achieved with LPS. The data indicate that none of the HT-2 stimulating activity can be attributed to either IL-2 or IL-4, the two major T cell growth factors. Although these cells do secrete M-CSF (38), ${ }^{3}$ biochemical analysis using gel filtration HPLC indicates that the HT-2 stimulating activity elutes at a molecular weight of between 20,000 and 30,000 . These data make it highly unlikely that the HT-2 stimulating activity is M-CSF, which elutes under similar conditions with a molecular weight of 70-10,000 (39). In addition, CM highly enriched in M-CSF
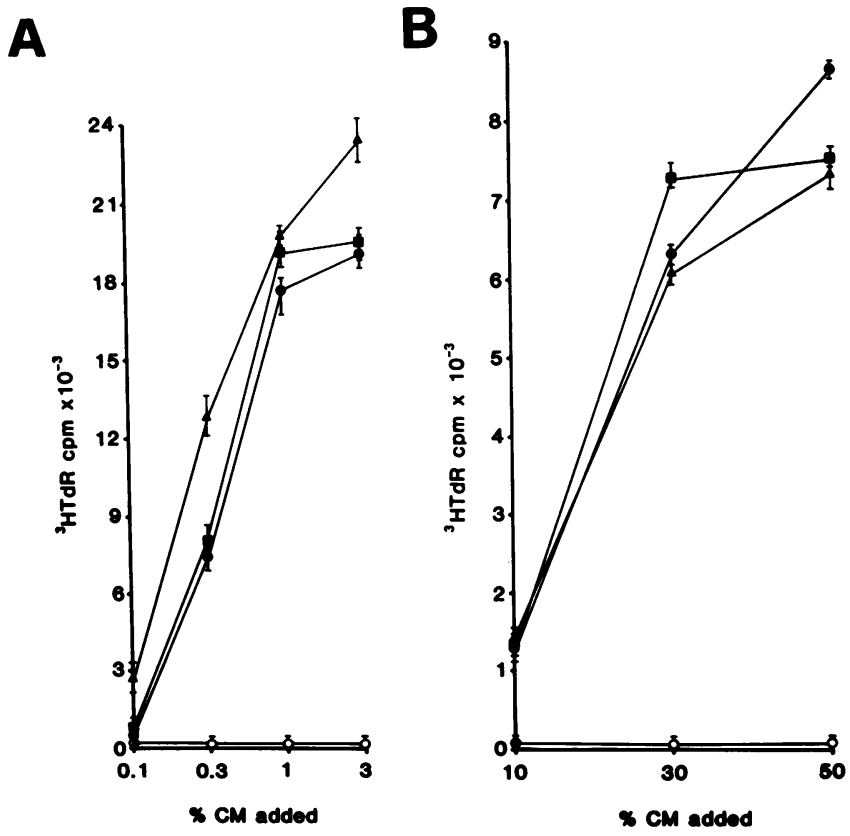

Figure 9. Neutralizing antibody analysis of CM from low density seeded bone cell cultures induced with either LPS or PTH. Varying concentrations of $\mathrm{CM}$ derived from cultures of low density seeded bone cells, induced with $(A) 10 \mu \mathrm{g} / \mathrm{ml}$ of LPS or $(B) 10 \mathrm{nM}$ PTH for $96 \mathrm{~h}$ were assayed for their ability to induce $\mathrm{T}$ cell proliferation in the absence (triangles) or presence of neutralizing antibodies to IL-2 (closed circles), IL-4 (squares) or GM-CSF (open circles). CM (50 $\mu$, $25 \% \mathrm{vol} / \mathrm{vol}$ ) was cocultured with the TCGF-dependent $\mathrm{T}$ cell clone HT-2 $\left(2 \times 10^{4}\right.$ cells/well $)$ plus $50 \mu 1$ of the appropriately diluted antibodies (anti-IL-2R 1:10; anti-IL-4 1:1,000; anti-GM-CSF 1:1,000) for $48 \mathrm{~h}$ in a final volume of $200 \mu \mathrm{l}$. Controls: HT-2 cells plus media $244 \pm 9$. 
does not induce HT-2 cell proliferation. ${ }^{3}$ Equally unlikely, is the factor reported by McSheehe, which is derived from osteosarcoma cells (UMR 106) that are induced with PTH (5). This material induces bone resorption and has a molecular weight of $<1,000$. The HT-2 stimulating activity of primary osteoblast derived CM can be blocked completely with a polyclonal goat antibody to murine GM-CSF. This antibody fails to show cross-reactivity with M-CSF, G-CSF, IL-3, IL-4, IL-2, and IL-1. ${ }^{2}$ In addition, we have shown that CM from both PTH and LPS stimulated osteoblasts is able to promote the formation of bone marrow colonies in soft agar. ${ }^{3}$ Three distinct morphological types of colonies could be discerned. First, tight clusters of round small cells which are granulocytes were present, although these were few in number. Second, loosely associated colonies of large cells which are macrophages were also found. Third and most numerous, were the large mixed type that contained both the small round cells and the larger macrophages. This pattern of colonies is characteristic of the types GM-CSF induces (40). These data in conjunction with the other functional and biochemical data strongly support the contention that the HT-2 stimulating activity is GM-CSF. We cannot however, completely eliminate the possibility that a unique cytokine with functional, biochemical, and antigenic characteristics similar to GM-CSF is not responsible for the observed activity. This possibility seems unlikely. Our data is consistent with and extends that of Felix et al. who has shown that $\mathrm{CM}$ from cultured whole murine calvaria and unseparated calvarial cells contains GM-CSF (41).

We have recently described a cytokine derived from murine keratinocytes with essentially identical functional and biochemical characteristics as the osteoblast-derived material (10). This factor is referred to as keratinocyte derived T cell growth factor or KTGF. We have purified this cytokine 47,000-fold and shown that it is GM-CSF (36).

The possibility exists that the GM-CSF activity we have observed is derived from cells other than the osteoblasts that are present in the cell preparation. Macrophages appear to be the most likely candidates as an alternative source of GM-CSF. We are not excluding the possibility that osteoclasts may also be a source of GM-CSF, especially if osteoclasts are members of the macrophage lineage $(42,43)$. Macrophages can release GM-CSF after activation with LPS (44). However, no data is available that addresses whether osteoclasts are able to secrete cytokines. The possibility that macrophages are the source of GM-CSF seems unlikely for the following reasons. First, the number of contaminating macrophages comprises $<0.1 \%$ of the total cells in the low density population and $<5 \%$ of the total cells in the high density population as determined by numbers of antibody dependent erythrophagocytic cells. The high density population produces less GM-CSF activity after LPS stimulation than the low density population even though it contains more macrophages. Second, osteoblasts but not macrophages possess receptors for PTH (45). In fact, monocytes are known to degrade the hormone (46). This would suggest that the ability of PTH to induce GM-CSF production in our cultures is the result of its action on cells other than macrophages. Third, we have been able to demonstrate that the rat derived, cloned osteosarcoma cell line ROS 17/2.8 and the cloned nontransformed murine osteoblastic cell line MC3T3-E1, which are maintained in vitro, and therefore do not contain any contaminating cell types, can also secrete GM-CSF when stimulated in a fashion similar to that used for the calvarial cells $(46 a, 47)$.
A second possibility is that $\mathrm{T}$ cells, one of the major sources of GM-CSF are responsible for the observed activity. Although LPS is not known to activate T cells, these cells are known to possess receptors for, and can be activated by PTH $(46,48,49)$. This possibility is also highly unlikely since few mature functional $\mathrm{T}$ cells are present in the periphery of neonatal mice (35). In addition, the CM used throughout these experiments is prepared from adherent bone cell monolayers. Nonadherent cells are removed by extensive washing. Quiescent $T$ cells are nonadherent.

It is interesting to note that the high density seeded cells routinely respond less vigorously to LPS and almost not at all to PTH, as measured by GM-CSF activity, in comparison to the low density seeded cells. This difference could be explained if the high density seeded population contained less cells per tissue culture well. This however, is not the case. In fact, the high density population has more cells per well than the low density population. The over riding population present in both cultures is actively growing preosteoblasts $(26,27)$. The nonosteoblastic cells account for only $5-10 \%$ of the total cells present in the high density seeded population. Therefore, it seems unlikely that this small percentage of cells could dilute the osteoblasts sufficiently to result in the reduced level of activity present in the high density seeded population. An alternative explanation for this diminished response is that the nonosteoblastic cells present in the high density population that are not present in the low density population may be actively inhibiting the osteoblasts from secreting the GM-CSF by the secretion of an inhibitor. TGF $\beta$ is a possible candidate for this inhibitory molecule. Bone cell CM contains TGF $\beta$, the activity of which can be increased following PTH stimulation (50) and it is an inhibitor of T cell growth (51). The possibility that TGF $\beta$ is inhibiting at the level of the assay is unlikely since HT-2 cell proliferation is insensitive to the effects of TGF $\beta .^{3}$ Another possibility is that the large amount of matrix present in the high density population, which can be seen with scanning electronmicroscopy, ${ }^{5}$ may be binding the growth factor in a fashion analogous to that seen with bone marrow matrix (52).

It has become apparent that bone cells and particularly osteoblasts not only participate in the regulation of skeletal homeostasis but may also function as a regulating component of hematopoiesis. In addition to the secretion of GM-CSF osteoblasts secrete what is apparently macrophage colony stimulating factor (38). This CSF is specific for macrophages, has similar functional activity to GM-CSF but is the product of a distinct gene (39). Thus osteoblasts secrete at least two of the four major CSFs making osteoblasts potentially significant regulatory cells in hematopoietic function. This is supported by the idea that osteoblasts are terminally differentiated members of the stromal cell family (53). One of the major functions of stromal cells is to secrete various cytokines that maintain the microenvironment required for hematopoiesis (54). The ability of osteoblasts to secrete GM-CSF and M-CSF is consistant with their stromal cell lineage.

It was thought until recently that the agents which induce osteoclastic bone resorption functioned by direct activation of the osteoclast. Included in this list of inducing agents was PTH, IL-1, TNF, and $1,25(\mathrm{OH})_{2}$ vitamin D3. Recent data suggest that this is not the case for many of these agents. Osteoclasts stimulated with PTH, IL-1, and TNF fail to resorb

5. Jilka, R., unpublished observation. 
bone unless they are cocultured with either osteoblasts or CM from cultures of osteoblasts (5-7). This is substantiated by the observation that osteoclasts do not have receptors for PTH while osteoblasts do (45). These data suggest that a soluble factor(s) is secreted by intermediate cells, which is required by osteoclasts to resorb bone. One obvious candidate for this intermediate cell is the osteoblast. MacDonald has shown that GM-CSF, and to a lesser extent M-CSF, when cocultured with bone marrow cells, results in the formation of cells with many of the characteristics of osteoclasts (13). Therefore, GM-CSF, which has previously been shown to be a product of T cells (8), keratinocytes (10), endothelial cells (9), and now of osteoblasts, may be participating in bone resorption by regulating osteoclasts in two ways. First, osteoblasts once activated by specific signals (i.e., PTH, LPS, IL-1, and TNF) release GMCSF. This cytokine works in a paracrine fashion, by leaving the bone and entering the adjacent marrow where it stimulates replication of multipotential progenitor cells (CFU-GM). Once acted upon these cells can differentiate to osteoclast precursors (55). These cells then become available for additional differentiation signals (i.e., $1,25(\mathrm{OH})_{2} \mathrm{D} 3$ ) to yield mature osteoclasts. This idea is consistent with the observations of Lorenzo et al. (12). Second, GM-CSF is known to exert functional changes in mature cells (56). These functional changes include activation of neutrophils and increased phagocytic activity (57). Osteoblast-derived GM-CSF may act alone or in concert with other cytokines to activate mature osteoclasts in a similar fashion to resorb bone.

The idea that osteoclast precusors are derived exclusively from granulocyte-macrophage-colony forming cells remains an open question in light of the data of Schneider and Relfson (58). They show that enriched populations of granulocyte (GCFC) and granulocyte-macrophage-colony forming cells (GM-CFC) derived from the bone marrow of normal littermates of incisor absent (ia) rats were effective in curing the osteopetrotic condition and giving rise to osteoclasts when adoptively transfered to incisor absent rats. On the other hand, macrophage-colony forming cells were totally ineffective in both curing the skeletal defect and giving rise to osteoclasts. One interpretation of this data is that the osteoclast precursor is in the granulocyte lineage. Alternatively, the precusors may have been co-purified with the G-CFCs.

Coupling factors are thought to be released by mononuclear phagocytes following the resorption phase and act on osteoblast precursors or osteoblasts to induce the formation of new bone (59). Although GM-CSF and other similar osteoblast derived cytokines are not coupling factors in the strict sense of the term, nonetheless these growth factors can be considered as promoting factors for bone resorption and function to link osteoblasts with osteoclasts.

\section{Acknowledgments}

The expert technical assistance of Ms. Monica Andreoli, Mr. Jonathan Keller, and Ms. Martha Germann is gratefully acknowledged.

This work was supported by The Veterans Administration and The Department of Orthopaedics and Rehabilitation, Yale University School of Medicine.

\section{References}

1. Bertolini, D. R., G. E. Nedwin, T. S. Bringman, D. D. Smith, and G. R. Mundy. 1986. Stimulation of bone resorption and inhibition of bone formation in vitro by human tumor necrosis factor. Nature (Lond.). 319:516-518.
2. Gowan, M., D. D. Wood, E. J. Ihrie, M. K. B. McGuire, and R. G. G. Russel. 1983. An interleukin 1 like factor stimulates bone resorption in vitro. Nature (Lond.). 306:378-380.

3. McSheehy, P. M. J., and T. J. Chambers. 1986. Osteoblastic cells mediate osteoclastic responsiveness to PTH. Endocrinology. 118:825828.

4. Jilka, R. L. 1986. Are osteoblastic cells required for the control of osteoclast activity by parathyroid hormone. Bone Miner. 1:261-266.

5. McSheehy, P. M. J., and T. J. Chambers. 1986. Osteoblast-like cells in the presence of parathyroid hormone release soluble factor that stimulates osteoblastic bone resorption. Endocrinology. 119:16541659.

6. Thomson, B. M., J. Saklavala, and T. J. Chambers. 1986. Osteoblasts mediate interleukin 1 stimulation of bone resorption by rat osteoclasts. J. Exp. Med. 164:104-112.

7. Thomson, B. M., G. R. Mundy, and T. J. Chambers. 1987. Tumor necrosis factors alpha and beta induce osteoblastic cells to stimulate osteoclastic bone resorption. J. Immunol. 138:775-779.

8. Parker, J. W., and D. Metcalf. 1974. Production of colony-stimulating factor in mitogen-stimulated lymphocyte cultures. J. Immunol. 112:502-510.

9. Quesenberry, P. J., and M. A. Gimbrone (1980). Vascular endothelium as a regulator of granulopoiesis. Production of colony stimulating activity by cultured human endothelial cells. Blood. 56:10601067.

10. Coleman, D. L., T. S. Kupper, P. M. Flood, C. C. Fultz, and M. C. Horowitz. 1987. Characterization of a keratinocyte-derived T cell growth factor distinct from interleukin 2 and B cell stimulatory factor 1. J. Immunol. 138:3314-3318.

11. Stanely, E. R., and P. M. Heard. 1977. Factors regulating macrophage production and growth. J. Biol. Chem. 252:4305-4312.

12. Lorenzo, J. A., S. L. Sousa, J. M. Fonseca, J. M. Hock, and E. S. Medlock. 1987. Colony stimulating factors regulate the development of multinucleated osteoclasts from recently replicated cells in vitro. $J$. Clin. Invest. 80:160-164.

13. MacDonald, B. R., G. R. Mundy, S. Clark, E. A. Wang, T. J. Kuehl, E. R. Stanley, and G. D. Roodman. 1986. Effects of human recombinant CSF-GM and highly purified CSF-1 on the formation of mutinucleated cells with osteoclast characteristics in long-term bone marrow cultures. J. Bone Miner. Res. 1:227-233.

14. Horowitz, M. C., A. Vignery, R. Jilka, and R. Baron. 1986. Characterization of immunologically functional cytokines released by cells present in bone. J. Bone Miner. Res. 1:116. (Abstr.)

15. Robb, R. J. 1984. Interleukin 2: the molecule and its function. Immunol. Today. 5:203-209.

16. Ferandez-Botran, R., V. M. Sanders, K. G. Olivers, Y. W. Chen, P. H. Krammer, J. W. Uhr, and E. S. Vitetta. 1986. Interleukin 4 mediates autocrine growth of helper $T$ cells after antigeneic stimulation. Proc. Natl. Acad. Sci. USA. 83:9689-9693.

17. Mosmann, T., H. Cherwinski, M. W. Bond, M. Geidlen, and R. L. Coffman. 1986. Two types of murine T helper cells. 1. Identification according to profile of lymphokine activities. J. Immunol. 136:2348.

18. Roehm, N., L. Herron, J. Cambier, D. DiGuisto, K. Haskins, J. Kappler, and P. Marrack. 1984. The major histocompatibility complex-restricted antigen receptor on $T$ cells: Distribution on thymus and peripheral T cells. Cell. 38:577-584.

19. Andersson, J., G. Möller, and O. Söberg. 1972. Selective induction of DNA synthesis in T and B lymphocytes. Cell. Immunol. 4:381.

20. Nicola, N. A., A. W. Burgess, and D. Metcalf. 1979. Similar molecular properties of granulocyte-macrophage colony stimulating factors produced by different mouse organs in vitro and in vivo. $J$. Biol. Chem. 254:5290-5299.

21. Jilka, R. L. 1986. Parathyroid hormone-stimulated development of osteoclasts in cultures of cells from neonatal murine calvaria. Bone. 7:29-49.

22. Wong, G. L., and D. V. Cohn. 1975. Target cells in bone for parathormone and calcitonin are different: enrichment for each cell 
type by sequential digestion of mouse calvaria and selective adhesion to polymeric surfaces. Proc. Natl. Acad. Sci. USA. 72:3167-3171.

23. Boonekamp, P. M., J. W. Hekkelman, J. W. Hamilton, D. V. Cohn, and R. L. Jilka. 1984. Effect of culture on the hormone responsiveness of bone cells isolated by an improved sequential digestion procedure. Proc. K. Ned. Akad. Wet. Ser. B. Biol. Med. Sci. 87:371381.

24. Centrella, M., T. L. McCarthy, and E. Canalis. 1987. Transforming growth factor beta is a bifunctional regulator of replication and collagen synthesis in osteoblast-enriched cell cultures from fetal rat bone. J. Biol. Chem. 262:2869-2874.

25. Jilka, R. L. 1987. Effects of PTH and lipopolysaccharide on osteoclast and mononuclear phagocyte development in cultured calvarial cells of normal and osteopetrotic $(\mathrm{mi} / \mathrm{mi})$ mice. J. Bone Miner. Res. 2(Suppl. 1):259. (Abstr.)

26. Simmons, D. J., G. N. Kent, R. L. Jilka, D. M. Scott, M. Mallon, and D. V. Cohn. 1982. Formation of bone by isolated cultured osteoblasts in millipore diffusion chambers. Calcif. Tissue Int. 34:29i-294.

27. Jilka, R. L., and D. V. Cohn. 1981. Role of phosphodiesterase in the parathormone-stimulated adenosine $3^{\prime} 5^{\prime}$-monophosphate response in bone cell populations enriched in osteoclasts and osteoblasts. Endocrinology. 109:743-747.

28. Kaye, J., S. Porcelli, J. Tite, B. Jones, and C. A. Janeway, Jr. 1983. Both a monoclonal antibody and antisera specific for determinants unique to individual cloned $T$ cell lines can substitute for antigen and antigen-presenting cells in the activation of T cells. J. Exp. Med. 158:836-856.

29. Kupper, T., P. Flood, D. Coleman, and M. Horowitz. 1987. Growth of an IL-2/IL-4 dependent T cell line induced by granulocytemacrophage colony stimulating factor (GM-CSF). J. Immunol. 138:4288-4292.

30. Watson, J. 1979. Continuous proliferation of murine antigenspecific helper T lymphocytes in culture. J. Exp. Med. 150:1510-1519.

31. Horowitz, M. C., A. Vignery; R. K. Gershon, and R. Baron. 1984. Thymus derived lymphocytes and their interactions with macrophages are required for the production of osteoclast activating factor in the mouse. Proc. Natl. Acad. Sci. USA. 81:2181-2185.

32. Wysocki, L. J. and V. L. Sato. 1978. Panning for lymphocytes: a method for cell selection. Proc. Natl. Acad. Sci. USA. 75:2844-2848.

33. Ohara, J., and W. E. Paul. 1985. Production of a monoclonal antibody to and molecular characterization of $B$ cell stimulatory factor 1. Nature (Lond.). 315:333-336.

33a. Gillis, S., and K. A. Smith. 1977. Long term culture of tumor-specific cytotoxic T cells. Nature (Lond.). 268:154-156.

34. Ho, S. N., R. T. Abraham, S. Gillis, and D. J. McKean. 1987. Differential bioassay of interleukin 2 and interleukin 4. J. Immunol. Methods. 98:99-104.

35. Katz, D. H. 1977. Ontogeny of the two major classes of lymphocytes. In Lymphocyte Differentiation, Recognition and Regulation. D. H. Katz, editor. Academic Press, New York. 119-151.

36. Kupper, T. S., F. Lee, D. Coleman, J. Chodakewitz, P. Flood, and M. Horowitz. 1988. Keratinocyte derived T cell growth factor (KTGF) is identical to granulocyte macrophage colony stimulating factor (GM-CSF). J. Invest. Dermatol. 91:185-188.

37. Farrar, J. J., M. Howard, J. Fuller-Farrar, and W. E. Paul. 1983. Biochemical and physiochemical characterization of mouse B cell growth factors. A lymphokine distinct from interleukin 2. J. Immunol. 131:1838.

38. Elford, P. R., R. Felix, M. Cecchini, U. Trechsel, and H. Fleisch. 1987. Murine osteoblast like cells and osteogeneic cell MC3T3-E1 release a macrophage colony stimulating activity in culture. Calcif. Tissue Int. 41:151-156.

39. Sieff, C. A. 1987. Hematopoietic growth factors. J. Clin. Invest. 79:1549-1557.

40. lizuka, Y., K. Noguchi, K. E. Schuebel, T. Miyake, and M. J. Murphy, Jr. 1985. A quantitative assay for mouse granulocyte (CFU-g) and macrophage (CFU-m) precurors using plasma clots. J. Histochem. Cytochem. 33:617-633.
41. Felix, R., P. R. Elford, C. Stoerckle, M. Cecchini, A. Wetterwald, U. Trechsel, H. Fleisch, and B. M. Stadler. 1988. Production of hematopoietic growth factors by bone tissue and bone cells in culture. J. Bone Miner. Res. 3:27-36.

42. Walker, D. G. 1975. Bone resorption restored in osteopetrotic mice by transplants of normal bone marrow and spleen cells. Science (Wash. DC). 190:784-785.

43. Kahn, A. J., C. C. Stewart, and S. J. Teitelbaum. 1978. Contact mediated bone resorption by human monocytes in vitro. Science (Wash. DC). 199:988-989.

44. Thorens, B., J. Mermod, and P. Vassalli. 1987. Phagocytosis and inflammatory stimuli induce GM-CSF mRNA in macrophages through posttranscriptional regulation. Cell. 48:671-679.

45. Pliam, N. B., K. D. Nyiredy, C. D. Arnaud. 1982. Parathyroid hormone receptors in avain bone cells. PNAS. 79:2061-2063.

46. Perry, H. M., J. C. Chappel, E. Bellorin-Font, J. Tamao, K. J. Martin, and S. L. Teitelbaum. 1984. Parathyroid hormone receptors in circulating human mononuclear leukocytes. J. Biol. Chem. 259:5531-5535.

46a. Weir, D., K. L. Insogna, and M. C. Horowitz. 1989. A clonal rat osteosarcoma line secretes a granulocyte-macrophage colony stimulating-like factor in response to parathyroid hormone and lipopolysaccharide. Endocrinology. In press.

47. Horowitz, M. C., J. T. Ryaby, and T. A. Einhorn. 1988. Differential production of colony stimulating factors by the murine osteoblastic cell line MC3T3. Second International Workshop on Cells and Cytokines in Bone and Cartilage. 1:74. (Abstr.)

48. Perry, H. M. 1986. Parathyroid hormone-lymphocyte interactions modulate bone resorption. Endocrinology. 119:2333-2339.

49. Rouleau, M. F., H. Warshawsky, and D. Goltzman. 1986. Parathyroid hormone binding in vivo to renal, skeletal and hepatic tissues of the rat using a radioautographic approach. Endocrinology. 118:919-931.

50. Pfeilschifter, J., and G. R. Mundy. 1987. Modulation of type $\beta$ transforming growth factor activity in bone cultures by osteotrophic hormones. Proc. Natl. Acad. Sci. USA. 84:2024-2028.

51. Kehrl, J. H., L. M. Wakefield, A. B. Roberts, S. Jakowlew, M. Alvez-mon, R. Derynck, M. B. Sporn, and A. S. Fauci. 1986. Production of transforming growth factor $\beta$ by human $T$ lymphocytes and its potential role in the regulation of $\mathrm{T}$ cell growth. J. Exp. Med. 163:1037-1050.

52. Gordon, M. Y., G. P. Riley, S. M. Watt, and M. F. Greaves. 1987. Compartmentalization of a haeatopoietic growth factor (GMCSF) by glycosaminoglycans in the bone marrow microenvironment. Nature (Lond.). 33:403-405.

53. Owen, M. 1985. Lineage of osteogenic cells and their relationship to the stromal system. In Bone and Mineral Research. Vol. 3. W. A. Peck, editor. Elsevier, Amsterdam. 1-25.

54. Lanotte, M., D. Metcalf, and T. M. Dexter. 1982. Production of monocyte/macrophage colony stimulating factor by predipocyte cell lines derived from murine marrow stroma. J. Cell. Physiol. 112:123127.

55. Chenu, C., N. Kurihara, C. Civin, and G. D. Roodman. 1988. CFU-GM are the probable precursors for osteoclasts. J. Bone Miner. Res. 3:s100. (Abstr.)

56. Grabstein, K. H., D. L. Urdal, R. J. Tushinski, D. Y. Mochizuk, V. L. Price, M. A. Cantrell, S. Gillis, and P. J. Conlon. 1986. Induction of macrophage tumoricidal activity by granulocyte-macrophage colony stimulating factor. Science (Wash. DC). 232:506-508.

57. Weisbart, R. H., D. W. Golde, S. C. Strong, G. G. Wong, and J. C. Gasson. 1985. Human granulocyte-macrophage colony stimulating factor is a neutrophil activator. Nature (Lond.). 314:361-363.

58. Schneider, G. B., and M. Relfson. 1988. The effects of transplantation of granulocyte-macrophage progenitors on bone resorption in osteopetrotic rats. J. Bone Miner. Res. 3:225-232.

59. Baron, R., A. Vignery, and M. C. Horowitz. 1983. Lymphocytes, macrophages and the regulation of bone remodeling. In Bone and Mineral Research. Annual 2. W. Peck, editor. Elsevier, Amsterdam. 175-243. 